University of Nebraska - Lincoln

DigitalCommons@University of Nebraska - Lincoln

Sociology Department, Faculty Publications

Sociology, Department of

2004

\title{
Victimization and Posttraumatic Stress Disorder Among Homeless Adolescents
}

\author{
Angela J. Stewart \\ University of Washington - Seattle Campus, stangela@u.washington.edu \\ Mandy Steiman \\ University of Washington - Seattle Campus \\ Ana Mari Cauce \\ University of Washington - Seattle Campus \\ Bryan N. Cochran \\ University of Montana - Missoula \\ Les B. Whitbeck \\ University of Nebraska-Lincoln, Iwhitbeck2@unl.edu \\ See next page for additional authors
}

Follow this and additional works at: https://digitalcommons.unl.edu/sociologyfacpub

Stewart, Angela J.; Steiman, Mandy; Cauce, Ana Mari; Cochran, Bryan N.; Whitbeck, Les B.; and Hoyt, Dan R., "Victimization and Posttraumatic Stress Disorder Among Homeless Adolescents" (2004). Sociology Department, Faculty Publications. 231.

https://digitalcommons.unl.edu/sociologyfacpub/231

This Article is brought to you for free and open access by the Sociology, Department of at DigitalCommons@University of Nebraska - Lincoln. It has been accepted for inclusion in Sociology Department, Faculty Publications by an authorized administrator of DigitalCommons@University of Nebraska - Lincoln. 


\section{Authors}

Angela J. Stewart, Mandy Steiman, Ana Mari Cauce, Bryan N. Cochran, Les B. Whitbeck, and Dan R. Hoyt 


\title{
Victimization and Posttraumatic Stress Disorder Among Homeless Adolescents
}

\author{
Angela J. Stewart, M.S., ${ }^{1}$ Mandy Steiman, M.S., ${ }^{1}$ Ana Mari Cauce, Ph.D., ${ }^{1}$ Bryan N. Cochran, \\ Ph.D., ${ }^{2}$ Les B. Whitbeck, Ph.D., ${ }^{3}$ and Dan R. Hoyt, Ph.D. ${ }^{3}$ \\ 1. University of Washington, Seattle \\ 2. University of Montana, Missoula \\ 3. University of Nebraska-Lincoln \\ Corresponding author - A. J. Stewart, University of Washington, Department of Psychology, \\ Box 351525, Seattle, WA 98195; email stangela@u.washington.edu
}

\begin{abstract}
Objective-To examine street victimization and posttraumatic stress symptoms among urban homeless adolescents and to test whether emotional numbing and avoidance represent distinct posttraumatic stress disorder (PTSD) symptom clusters.

Method-Structured, private interviews were conducted with homeless adolescents $(N=374)$ in the Seattle metropolitan area (95\% response rate) from 1995 to 1998.

Results - Eighty-three percent of street youths were physically and/or sexually victimized after leaving home. Approximately $18 \%$ of these youths met research criteria for PTSD. Results from a confirmatory factor analysis suggest that disaggregating symptoms of avoidance from symptoms of emotional numbing provides a better fit of the data than the current DSM-IV model in which these symptoms are combined in one factor.

Conclusions - Sexual and physical victimization are serious threats for homeless adolescents, and those who are victimized are at risk for PTSD. Results challenge the belief that symptoms of avoidance and numbing represent one unified cluster in this population.
\end{abstract}

Keywords: PTSD, homeless youth, street youth, victimization

$\mathrm{P}$ osttraumatic stress disorder (PTSD) has been documented among children and adolescents exposed to traumas such as wars, natural disasters, sexual abuse, and violence (Perrin et al., 2000). However, studies of PTSD among adult populations far outnumber those that focus on children and adolescents. Although adolescents are one of our nation's most victimized groups (Hashima and Finkelhor, 1999) and young people who are exposed to prolonged and repeated violence are at risk for developing PTSD (Fitzpatrick and Boldizar, 1993; Garrison et al., 1995), relatively few studies have examined the psychological impact of victimization among adolescents.

Young children are thought to respond differently than adults to traumatic events. However, traumatized adolescents are thought to display a symptom pattern similar to adults with PTSD (Perrin et al., 2000).
One consistent finding, in the child and adolescent literature, is that higher levels of exposure are related to increased PTSD symptoms (Fitzpatrick and Boldizar, 1993; LaGreca et al., 1996; Lonigan et al., 1991; Pynoos et al., 1987). Another consistent finding is that adult women are particularly vulnerable and are more likely than men to have a lifetime PTSD diagnosis (Kessler et al., 1995). Among younger populations, the evidence for a gender difference in PTSD is somewhat mixed. Some studies have found higher PTSD rates among females (e.g., Cuffe et al., 1998; Garrison et al., 1995; Shannon et al., 1994), while others have not (e.g., LaGreca et al., 1996; Pynoos et al., 1987). Few studies have examined gender differences in the expression of particular PTSD symptoms in child and adolescent samples.

Individuals who are separated from their parents at an early age are at greater risk for developing PTSD 
(Breslau et al., 1991). Homeless adolescents are therefore a particularly vulnerable group, as many have been removed from their family or forced out of their homes (Cauce et al., 2000). Once homeless, adolescents are likely to be victims of physical assault and sexual exploitation (Kipke et al., 1997; MacLean et al., 1999; Whitbeck et al., 1997). Moreover, research suggests that risk factors for homelessness overlap with risk factors for PTSD. For example, poverty, familial psychiatric illness, and child abuse are common among street youths (Janus et al., 1987; Kufeldt and Nimmo, 1987; Schaffner, 1998; Terrell, 1997) and are also related to increased PTSD risk (Davidson et al., 1991). Many homeless youths have other mental health problems associated with PTSD risk, such as depression, anxiety, and alcohol dependence (Cauce et al., 2000; McCaskill et al., 1998). Together these studies suggest that many homeless youths leave troubled home environments and may be at greater risk for developing PTSD.

Among adolescents, PTSD prevalence is estimated at $2 \%$ to $6 \%$ in community samples and $12 \%$ to $15 \%$ among those with a trauma history (Cuffe et al., 1998; Giaconia et al., 1995). Very few studies have examined the psychological effects of trauma among homeless youths. One study found that approximately $12 \%$ of homeless youths have symptoms consistent with PTSD (Morgan and Cauce, 1999). However, no other studies have reported rates of PTSD among homeless adolescents.

\section{PTSD Symptom Classification}

In recent years, researchers have questioned the validity of the existing PTSD symptom classification. Since PTSD was introduced in the DSM-III (American Psychiatric Association, 1980), the classification of symptoms has remained largely intact. Symptoms are classified into three clusters: (1) reexperiencing, (2) increased arousal, and (3) avoidance and numbing. While classification decisions were based on expert consensus, empirical research has not supported PTSD symptom dimensionality and, moreover, has suggested that avoidance and numbing may not represent a unified symptom group (Asmundson et al., 2000; King et al., 1998).

Although DSM-IV (American Psychiatric Association, 1994) classifies avoidance and emotional numbing together in one symptom cluster, these symptoms constitute different responses to traumatic experiences. Avoidance involves active attempts to push away reminders of the trauma, whereas emotional numbing is characterized by passive feelings of detachment, estrangement, and difficulty accessing a wide emotional range (Foa and Roth- baum, 1998). Distinguishing between symptoms of avoidance and numbing has been supported by factor analyses (Amdur and Liberzon, 2001; Asmundson et al., 2000; Buckley et al., 1998; Foa et al., 1995; King et al., 1998; Taylor et al., 1998). Further, researchers have suggested that attention should be paid to emotional numbing because it sets PTSD apart from other anxiety disorders. The presence of numbing symptoms is the best indicator for meeting full PTSD criteria, and individuals who exhibit emotional numbing symptoms may be more likely to develop chronic PTSD (Feeny et al., 2000; Foa et al., 1992; Garrison et al., 1995).

\section{Purposes and Hypotheses of Present Study}

The purposes of the present study are threefold: (1) to examine victimization and PTSD among an understudied and vulnerable population (i.e., homeless youths); (2) to examine gender differences in rates of PTSD and symptom expression in this population; and (3) to test competing models of PTSD symptom dimensionality in this population. Hypotheses included (1) females would be exposed to higher rates of sexual victimization than males, (2) males would be exposed to higher rates of physical victimization than females, (3) victimized females would report higher rates of PTSD symptoms and would therefore more often meet the criteria for PTSD than victimized males, and (4) the PTSD model that separates symptoms of avoidance from symptoms of emotional numbing would provide a better fit of the data than a model that combines these symptoms together in one factor.

\section{Method}

Participants were homeless youths from the greater Seattle metropolitan area. Approval for the Seattle Homeless Adolescent Research and Education project (SHARE) was granted by the Internal Review Board at the University of Washington, and data collection took place over a 3-year period beginning in 1995. Adolescents aged 13 to 21 years who were not physically in custody of the state and whose residence was unstable were eligible for participation. Unstable residence was defined as living away from the residence of a parent, guardian, or primary caretaker for at least 1 week, spending less than 4 nights at home in the previous week, and having no viable home in which to live. Youths in temporary foster care or in group homes were also eligible, but only two youths in temporary foster care participated.

Obtaining a random sample of nontraditional populations such as the homeless is next to impossible because the sampling frame cannot be defined (Wright et al., 1995). A systematic sampling strategy was employed to recruit participants for the study. Places where homeless youths spend time were identified and the sample was obtained from these locations. This approach was used to maximize recruitment efforts in areas where homeless youths were likely to be encountered and to expand the sample to include youths not receiving services. Some participants were recruited in 
outdoor locations known to be popular among homeless youths. Others were recruited through agencies, organizations, or shelters that provide services to homeless youths. Trained outreach workers who were knowledgeable about street culture made the recruitment contacts and interviewed the participants. The interviews took place in agencies, shelters, cafés, restaurants, libraries, parks, or other outdoor locations. Face-to-face, private interviews that lasted approximately 3 to 4 hours were conducted over 2 days, and youths were paid $\$ 25$ for their participation.

\section{Participants}

Ninety-five percent $(N=374)$ of 394 eligible youths who were asked to participate agreed to be interviewed. Participants were male $(54 \%)$ and female (46\%) homeless youths, aged 13 to 21 years $($ mean $=17.1, \mathrm{SD}=2.1)$. Nearly half were ethnic minorities $(47 \%)$, including American Indian (19\%), African American (18\%), Latino (7\%), and Asian American or Pacific Islander (3\%) youths. Most adolescents left home for the first time during their early teen years $($ mean $=13.3$ years, $\mathrm{SD}=3.0)$ and left home many more times after their first departure from home (mean $=8.5$ times, SD $=16.2$ ). Many were physically $(45 \%)$ or sexually $(28 \%)$ abused before leaving home. Some had completed high school or a GED $(14 \%)$, while others were currently enrolled in alternative $(36 \%)$ or regular education (8\%) programs. Many were neither attending school nor working on a GED $(41 \%)$.

\section{Measures}

Physical and Sexual Victimization. A victimization measure was designed for the study and included questions about exposure to serious physical harm, brought about by physical or weapon assault, and experiences with unwanted, coerced, or forced sexual contact since leaving home. Response choices were on a 4-point scale that ranged from 0 ("never") to 3 ("many times"). Participants were classified as trauma-exposed if they were physically or sexually victimized one or more times since becoming homeless. The internal consistency was high for the full victimization measure (Cronbach $\alpha=.95$, split half reliability $=.71$ ) and for the Sexual $(\alpha=.98)$ and Physical $(\alpha=.93)$ Victimization subscales.

PTSD. A PTSD measure was designed for the study and included 17 questions that corresponded with the DSM-IV PTSD symptoms. Response choices were on an 8-point scale that ranged from 0 ("never") to 7 ("once a day or more"). The measure demonstrated satisfactory psychometric properties. Internal consistency was high for the full measure of PTSD (Cronbach $a=.91$, split half reliability $=.78)$ and for the reexperiencing $(\alpha=.81)$, increased arousal $(\alpha=.79)$, and avoidance and numbing ( $\alpha=.77)$ symptom clusters. (This measure can be viewed at http://www.jaacap.com using the ArticlePlus feature. [Allegedly]) DSM-IV criteria for PTSD were used as a basis for classifying youths with a research equivalent of PTSD. Homeless youths were classified with PTSD if they (1) were exposed to at least one incident of physical and/or sexual victimization after leaving home; (2) had one or more reexperiencing symptoms, had three or more avoidance and/or numbing symptoms, and two or more increased arousal symptoms; (3) and rated each of these qualifying symptoms as occurring once a week or more (i.e., 5 or higher on an 8-point scale).

\section{Data Analyses}

Descriptive statistics were used to describe victimization and PTSD rates among homeless youths. Gender differences in victim- ization and PTSD symptoms were analyzed with $t$ tests (for continuous variables) and $\chi^{2}$ tests (for dichotomous variables). Confirmatory factor analysis (CFA) was used to confirm the factor structure of two PTSD models, and the $\chi^{2}$ difference test was used to compare the fit of the two models. The statistical software EQS 6.0 (Bentler, 1989) was used for the model comparison.

For the CFA, an a priori measure measurement model was specified (model 1) and compared to an alternative model (model 2). Model 1 was based on the DSM-IV symptom classification and contained three latent or unobserved variables (reexperiencing, increased arousal, and avoidance/numbing) that reflected the 17 measured indicators, or symptoms of PTSD. For model 2, the avoidance and numbing cluster was separated into two factors, and the resulting alternative model contained four latent variables that also reflected the 17 measured indicators of PTSD.

\section{Results}

\section{Victimization}

Within the full sample $(N=374)$, most homeless youths were exposed to at least one form of physical or sexual victimization since leaving home $(82.7 \%)$. Many were physically but not sexually victimized $(44.2 \%)$, some were both physically and sexually victimized $(31.0 \%)$, and a few were sexually but not physically victimized $(6.4 \%)$. Victimization results are presented in Table 1, which shows the proportion of youths who were victimized one or more times since leaving home. $\chi^{2}$ tests revealed gender differences in the types of traumas homeless youths encountered. While males were more often victims of physical threats and assaults, females were more often subjected to sexual exploitation and rape. Victimization rates did not vary by ethnicity $\left(x_{1}^{2}=2.78, p=.60\right)$; however, victimization was more likely among those with a history of child physical abuse $\left(\chi_{1}^{2}=13.49, p<.001\right)$ but not among those with a history of child sexual abuse $\left(\chi_{1}^{2}=2.39, p=.15\right)$.

\section{PTSD and Symptoms}

The results indicated that among victimized youths $(n=301), 17.7 \%$ had symptoms consistent with a diagnosis of PTSD. Among those victimized, $21.4 \%$ of females and $14.7 \%$ of males met the research criteria for PTSD. The results did not support the hypothesis that victimized females would have higher rates of PTSD than males $\left(X_{1}^{2}=2.14, p=.16\right)$. Table 2 includes the percentage of youths who met the research criteria for each PTSD symptom and the results of $t$ tests comparing PTSD symptom ratings for males and females. Although the results of the $\chi^{2}$ analysis did not support a gender difference in the rates of PTSD diagnosis among this sample of homeless youths, the results of $t$ tests 
Table 1. Physical and Sexual Victimization Since on Own: Gender Differences

\begin{tabular}{|c|c|c|c|c|c|c|}
\hline Event & $\begin{array}{r}\text { Total } \\
(N=373) \\
n(\%)\end{array}$ & $\begin{array}{r}\text { Females } \\
(n=170) \\
\text { Mean (SD) }\end{array}$ & $\begin{array}{r}\text { Males } \\
(n=203) \\
\text { Mean (SD) }\end{array}$ & $t(d f)$ & $95 \% \mathrm{CI}$ & $p$ \\
\hline Threatened with a weapon & $214(57.1)$ & $2.11(1.50)$ & $2.55(1.63)$ & $-2.70(371)$ & $-0.76,-0.12$ & .01 \\
\hline Assaulted and wounded with a weapon & $106(28.3)$ & $1.50(1.36)$ & $1.88(1.58)$ & $-2.45(371)$ & $-0.68,-0.07$ & .02 \\
\hline Made to touch someone sexually & $40(10.7)$ & $1.69(1.80)$ & $1.40(1.60)$ & $1.67(371)$ & $-0.05,0.64$ & .10 \\
\hline Made to expose self sexually in person or for a camera & $19(5.1)$ & $1.43(1.62)$ & $1.39(1.60)$ & $2.40(371)$ & $-0.29,0.37$ & .81 \\
\hline Kissed or touched sexually (buttocks, breast, genitals) & $112(29.9)$ & $2.21(1.77)$ & $1.55(1.58)$ & $3.81(371)$ & $0.32,1.00$ & $<.01$ \\
\hline Attempted or actual sexual penetration & 73 (19.5) & $1.92(1.75)$ & $1.40(1.53)$ & $3.06(371)$ & $0.19,0.85$ & $<.01$ \\
\hline
\end{tabular}

Event occurred one or more times since leaving home. $p$ values are for two-tailed tests. $\mathrm{CI}=$ confidence interval

for the individual symptoms revealed that females had higher ratings than males for six of the PTSD symptoms. Rates of PTSD did not differ according to ethnic group $\left(\chi_{1}^{2}=3.58, p=.47\right)$.

\section{Confirmatory Factor Analysis}

Table 3 shows the results of the fit indices for the CFA and the $\chi^{2}$ difference test for model 1 and model 2.
While the reexperiencing and arousal symptom clusters were the same in both models, the avoidance and numbing symptoms were clustered together in model 1 and separated in model 2. Multiple fit indices were examined to determine how well the data fit each model. The comparative fit index (CFI) and the root mean square error of approximation (RMSEA) were used to judge the fit of the model. The CFI is an indicator of fit that has values ranging from 0 (poor fit) to 1.0 (perfect fit).

Table 2. Posttraumatic Stress Symptoms: Gender Differences

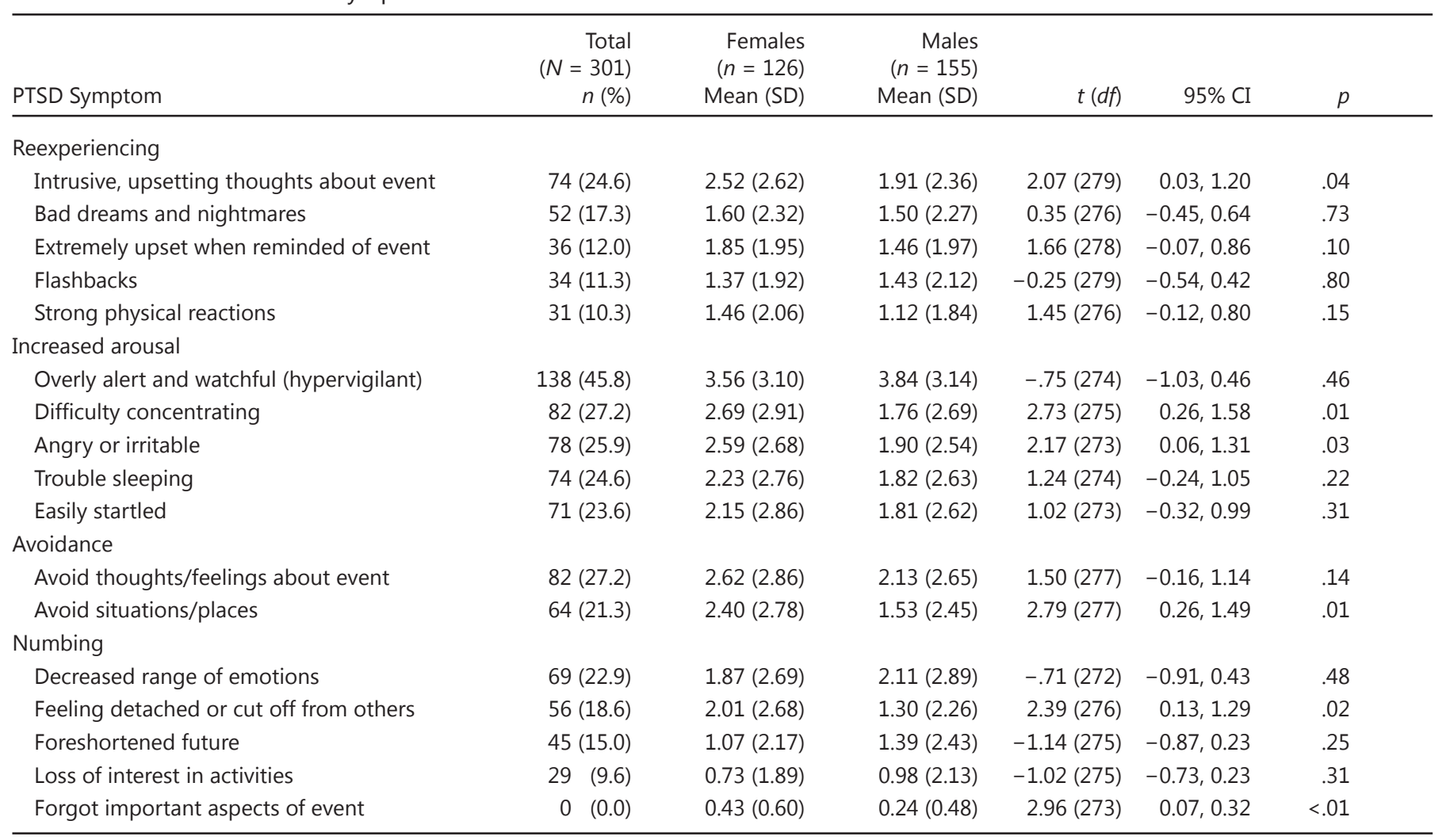

PTSD symptoms were considered "clinical" if youths experienced a symptom "once a week" or more often after exposure to victimization. $p$ values are for two-tailed tests; PTSD = posttraumatic stress disorder; $\mathrm{CI}=$ confidence interval. 
Table 3. Goodness-of-Fit Indices and $\chi^{2}$ Difference Tests for Nested Models

\begin{tabular}{|c|c|c|c|c|c|c|c|}
\hline \multirow[b]{2}{*}{ Model } & \multicolumn{4}{|c|}{ Fit Indices } & \multicolumn{3}{|c|}{$\begin{array}{l}\text { Difference } \\
\text { Between } \\
\text { Models }\end{array}$} \\
\hline & $x^{2}$ & $d f$ & RMSEA & CFI & $\overline{\Delta \chi^{2}}$ & $d f$ & $p$ \\
\hline Three-factor & 193.08 & 116 & 0.046 & 0.94 & & & \\
\hline Four-factor & 168.07 & 113 & 0.039 & 0.96 & 25.01 & 3 & $<.001$ \\
\hline
\end{tabular}

RMSEA = root mean square error of approximation; $C F I=$ comparative fit index; $\Delta \chi^{2}=$ change in $\chi^{2}$.

Values greater than 0.90 are considered to be consistent with good model fit (Bentler, 1990). The RMSEA is an index that takes into account the error of approximation in the population and indicates the expected goodness of fit if the entire population were included in the model. Good fit for the RMSEA are values lower than 0.05 , moderate fit are values between 0.05 and 0.08 , adequate fit are values 0.08 to 0.10 , and poor fit are values greater than 0.10 . The fit indices for both models were in the acceptable range. Results of the $\chi^{2}$ difference test indicated that when the avoidance and numbing symptoms were modeled as separate factors (model 2), the model was significantly improved over the model in which they were grouped together (model 1 ).

\section{Discussion}

\section{Victimization}

The results of the present study are consistent with other studies that found high rates of victimization among homeless adolescents (Kipke et al., 1997; MacLean et al., 1999). Moreover, the hypotheses that victimization rates differ according to gender were supported. Homeless males reported higher rates of physical victimization and females reported higher rates of sexual victimization. This finding is similar to other studies of housed (Hashima and Finkelhor, 1999) and homeless youths (Kipke et al., 1997).

\section{Posttrauma Symptoms and PTSD}

Among physically and/or sexually victimized youths, $17.7 \%$ met the research criteria for PTSD. These results are consistent with one past study of homeless adolescents (Morgan and Cauce, 1999) and suggest that PTSD is a serious mental health concern among street youths. Among other adolescent studies, reported rates of PTSD range from $12 \%$ of traumatized adolescents from community samples (Cuffe et al., 1998) to $27 \%$ of inner-city youths exposed to severe violence (Fitzpatrick and Boldizar, 1993). PTSD may be more common among high-risk populations such as the homeless because the risk for victimization is higher and factors associated with homelessness (e.g., disruptive home environments) are also associated with risk for developing PTSD (Breslau et al., 1991). Moreover, youths in highrisk environments may be more often exposed to multiple traumas.

Results of the present study are consistent with research that indicates that adolescents with PTSD are most likely to report difficulty concentrating, irritability, avoidance, and intrusive recollections (Fitzpatrick and Boldizar, 1993; Garrison et al., 1995). The high rates of hypervigilance reported by homeless youths are consistent with some studies (e.g., Fitzpatrick and Boldizar, 1993) but not with others (e.g., Garrison et al, 1995). Hypervigilance may be more common among youths immersed in high-risk environments where the threat of danger is constant than among adolescents who are able to return home after being exposed to trauma.

The results of the present study did not support the hypothesis that PTSD is more common among female homeless youths. These results were consistent with some studies (e.g., LaGreca et al., 1996; Pynoos et al., 1987) but not others (e.g., Breslau et al., 1991; Garrison et al., 1995; Shannon et al., 1994). While there were no gender differences in diagnostic classification of PTSD, females reported higher rates of some symptoms, such as difficulty concentrating, anger, avoidance, and numbing. Homeless females were more likely than males to be sexually exploited and raped. It has been suggested that gender differences in PTSD symptoms may be attributed to the increased exposure to sexual assaults among females (Giaconia et al., 1995; Kessler et al., 1995).

\section{PTSD Model Comparison}

The results of the CFA supported the hypothesis that symptoms of avoidance and emotional numbing are better represented as separate symptom groups among homeless adolescents. Consistent with a small body of literature, avoidance and numbing do not seem to constitute a unified factor, but rather represent two distinct factors (Asmundson et al., 2000; King et al., 1998). These findings are consistent with research suggesting that emotional numbing is a distinguishing feature of PTSD and may be predictive of more chronic symptomatology (Feeny et al., 2000; Foa et al., 1995; Garrison et al., 1995). 


\section{Limitations}

Structured clinical interviews with validated measures of PTSD were not within the scope of this study. While we were able to demonstrate high internal consistency for these measures, more work is needed to demonstrate their validity. Moreover, criterion A (i.e., the response to the event involved intense fear, helplessness, or horror) and criterion F (i.e., presence of clinically significant impairment and symptoms that lasted 1 month or more) from $D S M-I V$ were not directly assessed. In addition, the link between victimization and PTSD was not necessarily established. Many youths were victimized more than one time and their PTSD symptoms were not linked to any specific incident. Lastly, results of this study may not be generalizable to other samples of adolescents, especially those adolescents who have not experienced homelessness.

\section{Clinical Implications}

The present study demonstrates that homeless youths are frequently victimized and most must cope with very real threats to their physical safety. Negotiating street life is difficult for most teens (McCarthy and Hagan, 1992). However, caring for the most basic needs, such as finding food and shelter, is even more daunting when coupled with worry about avoiding victimization. The effects of victimization on this vulnerable population may be particularly harmful. For example, traumatized youths may expend emotional resources fearing or anticipating victimization and have few resources left to devote toward securing daily needs and planning for a better future.

Recovery from PTSD may be particularly challenging for homeless adolescents for several reasons. Those who are homeless will likely have difficulty finding safe living environments and locating appropriate therapeutic and financial resources. Treatment providers should be sensitive to issues that may be relevant to homeless populations. For example, Foa and Meadows (1997) suggest conducting a careful safety assessment before constructing in vivo hierarchies. However, it may be difficult to treat some PTSD symptoms, such as avoidance and hyperarousal, until a youth is in a less dangerous living situation.

While it is feasible that some PTSD symptoms, such as hypervigilance and avoidance, may help protect adolescents from future victimization, persistent symptoms may also lead to long-term psychological and emotional negative outcomes. For example, high levels of physiological arousal, troubled thoughts, and emotional numb- ing may have adverse consequences on emotional processing (Litz, 1992) and may impede typical courses of social and emotional development during adolescence. Emotional numbing may be particularly debilitating for homeless youths. The difficulty of seeking help, improving life circumstances, or simply making it through the day may be increased for those who feel emotionally detached from those who could provide support in negotiating these challenges.

The present study lends itself to several recommendations for providers of services to homeless youths. Medical care, safe places to stay, legal support, and counseling and therapy may be helpful for physically victimized youths. Immediate services, such as referrals to sexual assault clinics or testing and treatment for sexually transmitted diseases, may be necessary for those who are raped. Sexually exploited youths may need material supports to decrease dependence on their perpetrators for food or places to stay. They may also need legal support to prosecute perpetrators and long-term emotional support to cope with their trauma experience. Appropriate PTSD interventions that are relatively brief or that are likely to promote adherence among a highly transient population may be beneficial.

\section{Future Directions}

The present study highlights the physical and psychological risks associated with homelessness. More work is needed to understand the long-term effects of PTSD on the functioning of homeless youths. Future research directions include an examination of factors that predict victimization and the relationship of these predictors to the maintenance of PTSD symptoms over time.

Acknowledgments - The authors thank the homeless youths who participated in this study and all of the research staff whose dedication and hard work made this research possible. Ana Mari Cauce received research funding from NIAAA and NIMH and is a consultant to Learning Point Association. Les Whitbeck and Dan R. Hoyt received research funding from NIMH and NIDA.

\section{References}

Amdur RL, Liberzon I (2001), The structure of posttraumatic stress disorder symptoms in combat veterans: a confirmatory factor analysis of the Impact of Event Scale. J Anxiety Disord 15:345-357

American Psychiatric Association (1980), Diagnostic and Statistical Manual of Mental Disorders, 3rd edition (DSM-III). Washington, DC: American Psychiatric Association 
American Psychiatric Association (1994), Diagnostic and Statistical Manual of Mental Disorders, 4th edition (DSM-IV). Washington, DC: American Psychiatric Association

Asmundson GJG, Frombach I, McQuaid J, Pedrelli P, Lenox R, Stein MB (2000), Dimensionality of posttraumatic stress symptoms: a confirmatory factor analysis of DSM-IV symptom clusters and other symptom models. Behav Res Ther 38:203-214

Bentler P (1989), EQS Structural Equations Program Manual. Los Angeles: BMDP Statistical Software

Bentler PM (1990), Comparative fix indexes in structural models. Psychol Bull 107:238-246

Breslau N, Davis GC, Andreski P, Peterson E (1991), Traumatic events and posttraumatic stress disorder in an urban population of young adults. Arch Gen Psychiatry 48:216-222

Buckley TC, Blanchard EB, Hickling EJ (1998), A confirmatory factor analysis of posttraumatic stress symptoms. Behav Res Ther 36:1091-1099

Cauce AM, Paradise M, Ginzler JA et al. (2000), The characteristics and mental health of homeless adolescents: age and gender differences. J Emotion Behav Disord 8:230-239

Cuffe SP, Addy CL, Garrison CZ et al. (1998), Prevalence of PTSD in a community sample of older adolescents. J Am Acad Child Adolesc Psychiatry 37:147-154

Davidson JR, Hughes D, Blazer DG, George LK (1991), Posttraumatic stress disorder in the community: an epidemiological study. Psychol Med 21:713-721

Feeny NC, Zoellner LA, Fitzgibbons LA, Foa EB (2000), Exploring the roles of emotional numbing, depression, and dissociation in PTSD. J Trauma Stress 13:489-498

Fitzpatrick KM, Boldizar JP (1993), The prevalence and consequences of exposure to violence among African-American youth. J Am Acad Child Adolesc Psychiatry 32:424-430

Foa EB, Meadows EA (1997), Psychosocial treatments for posttraumatic stress disorder: a critical review. Ann Rev Psychol 48:449-480

Foa EB, Riggs DS, Gershuny BS (1995), Arousal, numbing, and intrusion: symptom structure of PTSD following assault. Am J Psychiatry 152:116-120

Foa EB, Rothbaum BO (1998), Treating the Trauma of Rape: Cognitive- Behavioral Therapy for PTSD. New York: Guilford

Foa EB, Zinbarg R, Rothbaum BO (1992), Uncontrollability and unpredictability in post-traumatic stress disorder: an animal model. Psychol Bull 112:218-238

Garrison CZ, Bryant ES, Addy CL, Spurrier PG, Freedy JR, Kilpatrrick DG (1995), Posttraumatic stress disorder in adolescents after Hurricane Andrew. J Am Acad Child Adolesc Psychiatry 34:1193-1201

Giaconia RM, Reinherz HZ, Silverman AB, Pakiz B, Frost AK, Cohen E (1995), Traumas and posttraumatic stress disorder in a community population of older adolescents. J Am Acad Child Adolesc Psychiatry 34:1369-1380

Hashima PY, Finkelhor D (1999), Violent victimization of youth versus adults in the National Crime Victimization Survey. J Interpers Viol 14:799-820

Janus MD, Burgess AW, McCormack A (1987), Histories of sexual abuse in adolescent male runaways. Adolescence 22:405-417

Kessler R, Sonnega A, Bromet E, Hughes M, Nelson C (1995), Posttraumatic stress disorder in the National Comorbidity
Survey. Arch Gen Psychiatry 52:1048-1060

King DW, Leskin GA, King LA, Weathers FW (1998), Confirmatory factor analysis of the clinician-administered PTSD Scale: evidence for the dimensionality of posttraumatic stress disorder. Psychol Assess 10:90-96

Kipke MD, Simon TR, Montgomery SB, Unger JB, Iversen EF (1997), Homeless youth and their exposure to and involvement in violence while living on the streets. J Adolesc Health 20:360-367

Kufeldt K, Nimmo M (1987), Kids on the street they have something to say: survey of runaway and homeless youth. J Child Care 3:53-61

LaGreca AM, Silverman WK, Vernberg EM, Prinstein MJ (1996), Symptoms of posttraumatic stress in children after Hurricane Andrew: a prospective study. J Consult Clin Psychol 64:712-723

Litz BT (1992), Emotional numbing in combat-related posttraumatic stress disorder: a critical review and reformulation. Clin Psychol Rev 12:417-432

Lonigan CJ, Shannon MP, Finch AJ, Daugherty TK, Taylor CM (1991), Children's reactions to a natural disater: symptom severity and degree of exposure. Adv Behav Res Ther 13:135-154

MacLean MG, Embry LE, Cauce AM (1999), Homeless adolescents' paths to separation from family: comparison of family characteristics, psychological adjustment, and victimization. J Comm Psychol 27:179-187

McCarthy B, Hagan J (1992), Surviving on the street: the experiences of homeless youth. J Adolesc Res 7:412-430

McCaskill PA, Toro PA, Wolfe SM (1998), Homeless and matched housed adolescents: a comparative study of psychopathology. J Clin Child Psychol 27:306-319

Morgan CJ, Cauce AM (1999), Predicting DSM-III-R disorders from the Youth Self-Report: analysis of data from a field study. J Am Acad Child Adolesc Psychiatry 38:1237-1245

Perrin S, Smith P, Yule W (2000), Practitioner review: the assessment and treatment of post-traumatic stress disorder in children and adolescents. J Child Psychol Psychiatry 41:277-289

Pynoos RS, Frederick C, Nader K et al. (1987), Life threat and posttraumatic stress in school-age children. Arch Gen Psychiatry 44:1057-1063

Schaffner L (1998), Searching for connection: a new look at teenaged runaways. Adolescence 33:619-627

Shannon MP, Lonigan CJ, Finch AJ, Taylor CM (1994), Children exposed to disaster, I: epidemiology of post-traumatic symptoms and symptom profiles. J Am Acad Child Adolesc Psychiatry 33:80-93

Taylor S, Kuch K, Koch WJ, Crockett DJ, Passey G (1998), The structure of posttraumatic stress symptoms. J Abnorm Psychol 107:154-160

Terrell NE (1997), Street life: aggravated and sexual assaults among homeless and runaway adolescents. Youth Society 28:267-290

Whitbeck LB, Hoyt DR, Ackerly KA (1997), Abusive family backgrounds and later victimization among runaway and homeless adolescents. J Res Adolesc 7:375-392

Wright JD, Allen TL, Devine JA (1995), Tracking non-traditional populations in longitudinal studies. Eval Program Plann 18:267-277 